\title{
A inovação-restauração das formas democrático- burguesas como característica da revolução passiva no Brasil
}

\author{
Cláudia Maria Costa Gomes ${ }^{1}$ \\ https://orcid.org/0000-0002-9366-3107
}

\author{
Ana Karoline Nogueira de Souza ${ }^{2}$ \\ https://orcid.org/0000-0002-7708-4738
}

${ }^{1}$ Universidade Federal da Paraíba, Programa de Pós-Graduação em Serviço Social, João Pessoa, PB, Brasil

${ }^{2}$ Universidade Federal da Paraíba, Programa de Pós-Graduação em Serviço Social, João Pessoa, PB, Brasil

\begin{abstract}
A inovação-restauração das formas democrático-burguesas como característica da revolução passiva no Brasil

Resumo: A análise apresentada neste artigo objetiva retomar os elementos da formação social brasileira com enfoque nas características da democracia e as formas da dominação burguesa realizada no Brasil. Desse modo, buscou-se compreender a complexidade da realidade social a partir da teoria social de Marx e através da metodologia da tradutibilidade foi possível aplicar a categoria gramsciana de revolução passiva na realidade brasileira. A ampla incursão bibliográfica apontou que a reprodução das relações sociais incide nos limites da emancipação política brasileira e avança para formas orgânicas antidemocráticas. Concluímos, portanto, que a revolução pelo alto se constitui como uma determinação do capitalismo dependente.
\end{abstract}

Palavras-chave: Estado. Capitalismo brasileiro. Revolução passiva. Democracia.

\section{The innovation-restoration of bourgeois-democratic forms as a characteristic of the passive revolution} in Brazil

Abstract: The analysis presented in this article aims to revisit the elements of the Brazilian social formation focusing on the democracy issues and the forms that the bourgeois domination takes in Brazil. Thus, it was sought to understand the complexity of social reality from Marx's social theory and through the methodology of translatability it was possible to apply the Gramscian category of passive revolution in Brazilian reality. The wide bibliographic incursion pointed out that the reproduction of social relations affects the milestones of Brazilian political emancipation and advances to undemocratic organic forms. We therefore conclude that revolution from above constitutes a determination of dependent capitalism.

Keywords: State. Brazilian capitalism. Passive revolution. Democracy.

Recebido em 31.10.2019. Aprovado em 11.02.2020 . Revisado em 31.03.2020

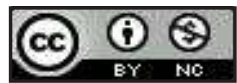

(C) O(s) Autor(es). 2020 Acesso Aberto Esta obra está licenciada sob os termos da Licença Creative Commons Atribuição-NãoComercial 4.0 Internacional (https://creativecommons.org/licenses/by-nc/4.0/deed.pt_BR), que permite copiar, distribuir e reproduzir em qualquer meio, bem como adaptar, transformar e criar a partir deste material, desde que para fins não comerciais e que você forneça o devido crédito aos autores e a fonte, insira um link para a Licença Creative Commons e indique se mudanças foram feitas. 


\section{Introdução}

A revolução 'democrática' e a revolução socialista se encontram em lados opostos da barricada (TROTSKY, 2010)

As questões candentes e atuais ligadas à democracia representativa brasileira que culmina no golpe parlamentar de 2016 são plenas de consequências e nos sugere levantar duas ideias que são colocados em uma: i) os desdobramentos advindos com o impeachment de Dilma Rousseff (2011-16) e a eleição do Presidente Bolsonaro em 2018 resultam da contradição entre a formação do capitalismo periférico brasileiro e as demandas democrático-burguesas de 1988, contra restadas pelo choque neoliberal produzido pela hegemonia burguesa do lulo-petismo, que se cristalizaram por meio do Estado e das relações com as frações de classe no poder (GOMES, 2018); ii) tais contradições, de antemão se apresentam desde a campanha das Diretas Já em 1984, passando pelas articulações da pré-Constituinte em 1987, as quais produziu no país a formação de blocos suprapartidários (NOBRE, 2016), que a partir do governo Sarney (1985-90), ronda como um espectro na vida política nacional, demonstrando a um só tempo, as limitações e distorções da restauração democrática instituída pelo alto no interregno da transição ditatorial militar iniciada em $1973^{1}$. Talvez essa situação histórica explique não apenas a real polarização e acomodação amorfa de posições políticas produzidas nos últimos anos no país, mas, sobretudo, a dificuldade de pensar um Brasil do ângulo de sua transformação e não de sua acomodação, o que supõe inserir na reflexão teórica as grandes questões que dizem respeito à formação social brasileira, em particular o caráter da revolução burguesa e sua impossibilidade de realização em um país de capitalismo dependente, o qual é objeto dessa reflexão ${ }^{2}$.

É, portanto, para entender o presente que surge a necessidade imprescindível de examinar as lições da história e nela, observamos que as estratégias da burguesia para ascender ao poder do Estado, resultam em um crescente e reiterado desmantelamento da organização da classe trabalhadora, por meio de um complexo movimento de passivização, que é orgânica a formação e dinâmica do capitalismo brasileiro e seus respectivos esquemas de dominação. As pistas de Gramsci nos colocaram diante da importância de observar através do conceito de revolução passiva, como a interpretação da revolução burguesa brasileira foi tratada por um grande e importante setor do pensamento social brasileiro, que ao abordar os acontecimentos históricos da conjuntura brasileira pela via democrática, consideravam que o país no final dos anos 1970 havia se consolidado como capitalista moderno. Também os conceitos de via prussiana de modernização, revolução-restauração e modernização conservadora, tornaram-se abrangentes na análise da formação social brasileira. Supomos que estas elaborações reflete parte de um movimento amplo da sociedade civil brasileira nos anos 1970-80, que tinha como base um programa de lutas direcionado para a construção de uma sociedade alforriada dos grilhões da autocracia burguesa no país e que foi acompanhada pelas mudanças econômicas na dinâmica do capitalismo brasileiro e do imperialismo à época. Conduzido assim, a interpretação da revolução burguesa

Nesse sentido, o conceito de revolução passiva nos permite refletir sobre os problemas e limites da democracia a partir de uma análise sobre o caráter do Estado e sua relação com as classes, amalgamada entre a burocracia e o patrimonialismo, entre as classes médias e as oligarquias reacionárias, que aliado ao controle das classes subalternas e seu subversivismo frequente, incide na conformação de dirigentes incapazes de levar adiante programas de ação que expresse reivindicações democráticas legitimas e consequentes com os interesses antagônicos ao capital. brasileira se diferencia radicalmente das proposições precedentes ${ }^{3}$ e sinaliza claramente que a diferença transitou da perspectiva política centrada no debate do nacional desenvolvimentismo das décadas anteriores (Cepal, Iseb e PCB $)^{4}$ para a questão do socialismo democrático. Não cabe, nesse espaço, entrar no debate diverso das 
produções realizadas e pesquisas vastamente publicadas nesse campo temático, mas apontar alguns elementos de reflexão sobre a formação social brasileira, que no nosso entendimento é chave de explicação para o modelo de desenvolvimento desigual e combinado como problema histórico do país, subscrito e reiterado pelo caráter predatório do Estado burguês e das "relações arcaicas" de sempre (OLIVEIRA, 1997).

Em última instância, o artigo justifica-se pela urgência imprescindível de percorrer os sendeiros do passado (para tentar encontrar as respostas do presente) a partir dos grandes intérpretes do Brasil inscritos nas mais diversas correntes do pensamento social, os quais questionaram sobre a formação da sociedade nacional, a organização do poder estatal, a sociedade patriarcal (oligarquias, clãs, família, casa-grande, parentesco...), o estatuto cultural, a literatura, a religião e a política. Em meio a essa vastidão de possibilidades e direcionamentos teóricos e políticos, algumas questões parecem-nos fundamentais para entender, por um lado, os traços estruturais de nossa formação social e, por outro, as características particulares da experiência da frente democráticopopular do lulo-petismo no âmbito da luta de classes no Brasil; que nos limites do artigo não nos permite problematizar.

Interessa-nos destacar que a via à modernização democrático brasileira foi realizada por meio do atraso social, contraditoriamente reproduzido para formas mais avançadas, sedimentares e orgânicas. Nossa conjectura é que esse fenômeno decorre da característica da contrarrevolução burguesa no Brasil, da particularidade do "Estado Nação", do caldo cultural disseminado pelas elites dominantes, da conformação das classes sociais em presença e da produção de consenso e coerção no exercício da hegemonia. Essas particularidades analisadas desde uma leitura gramsciana nos conduzem ao debate da revolução passiva, que como se sabe é um conceito abstrato que qualifica um tipo especial de regime que pressupõe uma contrarrevolução preventiva, comandada pela hegemonia das frações de classe burguesa e do Estado. Hegemonia que se realiza através do transformismo, que é uma das formas históricas da revolução passiva, isto é, "por uma combinação da força e do consenso que se equilibram, sem que a força suplante em muito o consenso, ao contrário, apareça apoiada pelo consenso da maioria" (GRAMSCI, Q. 1, § 48, p. 59, apud, ALIAGA, 2016, grifo nosso).

Nesse sentido, o conceito de revolução passiva nos permite refletir sobre os problemas e limites da democracia a partir de uma análise sobre o caráter do Estado e sua relação com as classes, amalgamada entre a burocracia e o patrimonialismo, entre as classes médias e as oligarquias reacionárias, que aliado ao controle das classes subalternas e seu subversivismo frequente, incide na conformação de dirigentes incapazes de levar adiante programas de ação que expresse reivindicações democráticas legitimas e consequentes com os interesses antagônicos ao capital.

Partindo desses pressupostos, estamos convencidas de que as características estruturantes de nossa formação social devem, com rigor, ser recuperadas para ampliar nossa leitura do presente com o objetivo de melhor explicá-la. À vista disso, o conceito de revolução passiva consiste em um critério de interpretação da revolução burguesa brasileira, uma vez que nesse processo estão presentes os determinantes principais da revolução sem revolução, ou revolução pelo alto. Desse modo, é por meio da metodologia da tradutibilidade 5 que é possível utilizar as categorias e os conceitos de Gramsci para analisar outras nacionalidades e assim, colocar na ordem do dia, as grandes teses explicativas sobre as especificidades da natureza da revolução burguesa, a exemplo do Brasil. Isso nos leva a rever alguns aspectos desprezíveis sobre o Estado no Brasil e suas formas de governo, que obstante ter transitado da autocracia ditatorial ao Estado democrático de direito, soube "combinar, aprimorar e fortalecer tanto os aspectos de busca de formação de consenso momentâneos, como os instrumentos antigos e novos de coerção" (IASI, 2019, p. 421).

\section{A Revolução Passiva à brasileira}

O processo de formação do Estado burguês no Brasil, a partir da revolução de 1930, não ocorreu de maneira jacobina, mas, ao contrário, modernizou-se pelo alto por meio da conciliação entre as diferentes frações das classes hegemônicas, o que reforça o caráter autoritário da dominação de classe própria dessa constituição Estatal. Esse movimento foi marcado pela ausência da participação unitária das massas populares e também houve o acolhimento de certa parte das exigências dos de baixo. Estes elementos, que caracterizam a transição para o capitalismo pela "via não clássica", nos remete a uma interpretação desse processo por meio da categoria gramsciana de revolução passiva.

Nos países latino-americanos, como o Brasil, a revolução burguesa é analisada por Aricó (1988) como revoluções derradeiras, uma vez que ocorrem tardiamente quando comparadas aos países centrais do capitalismo. Esse processo foi analisado fortemente pelos estudiosos da formação social brasileira nos anos 1970 e 1980 e produziu-se uma extensa bibliografia, na qual se destacaram Coutinho (1988) e Vianna (1976). Esses autores buscaram definir a revolução burguesa brasileira através da associação entre o conceito gramsciano de revolução passiva e o leninista de via prussiana. No entanto, cabe aqui ressaltar a crítica ao uso complemen- 
tar entre esses conceitos, realizada por Aricó (1988), uma vez que, segundo o autor, essa maneira de colocar o problema esmaga a capacidade analítica da categoria gramsciana.

Como afirmamos, no Brasil as alianças firmadas com os setores de agroexportação possibilitaram a passagem para o capitalismo industrial mediante um processo gradual. Desse modo, na revolução passiva brasileira, o Estado moderniza-se molecularmente, mas conserva o equilíbrio das alianças realizadas entre a burguesia industrial e a agroexportadora desde o período do Império. Esse processo de mudança molecular na revolução passiva brasileira assemelha-se a formação do Estado burguês Italiano, referindo-se ao Risorgimento Gramsci aponta que,

A revolução passiva se verificaria no fato de transformar a economia 'reformisticamente' de individualista para economia de segundo um plano (economia dirigida) e o advento de uma 'economia média' entre aquela individualista pura e aquela segundo um plano integral, permitiria a passagem a formas políticas e culturais mais progredidas sem cataclismos radicais destrutivos de forma arrasadora (GRAMSCI, 1975, p.1089 apud DEL ROIO, 2009).

Em concordância com Gramsci, ao descrever com um maior detalhamento o processo de mudança molecular no CC15 §56, os protagonistas desse movimento são os fatos e não os homens individuais:

[...] Como sob um determinado invólucro político, necessariamente se modificam as relações sociais fundamentais e novas forças políticas efetivas surgem e se desenvolvem, as quais influenciam indiretamente, com pressão lenta mais incoercível, as forças oficiais, que elas próprias, se modificam sem se dar conta, ou quase (GRAMSCI, CC 15, § 56, p.328).

Tendo em vista que a história é definida por Gramsci como uma sucessão de momentos de propulsão e de retração, de inovação e de conservação, no momento da revolução passiva esse processo é simultâneo e não diacrônico. Assim, queremos destacar a restauração progressista através da modificação na composição das forças sociais, que se evidencia pelo fato de a nascente burguesia industrial brasileira ter realizado um processo de industrialização no qual adequou às velhas estruturas das oligarquias agrárias. Desse modo, compreendemos que esse processo ocorreu por meio de uma "modernização pelo alto", como afirmamos anteriormente.

Sob esse aspecto, uma das fórmulas explicativas da revolução passiva em Gramsci é a inovação-conservação, que é chave-explicativa para analisarmos o processo da revolução de 1930 no Brasil, como revolução passiva. Com isso, verificamos que ao tempo em que a burguesia industrial emergente ascende no cenário político brasileiro não ocorre uma retirada do poder das oligarquias agrárias. Há, nesse momento, uma propulsão no sentido inovador da economia com o processo de industrialização, mas a velha relação política se conserva através da aliança entre a burguesia emergente com as arcaicas oligarquias agrárias, uma vez que aquelas são dependentes destas. Portanto, o processo de modernização capitalista brasileiro não passou por uma revolução democrático-burguesa de tipo jacobina, como explica Coutinho:

Por um lado, gradualmente e 'pelo alto', a grande propriedade latifundiária transformou-se em empresa capitalista agrária e, por outro, com a internacionalização do mercado interno, a participação do capital estrangeiro contribuiu para reforçar a conversão do Brasil em país industrial moderno, com uma alta taxa de urbanização e uma complexa estrutura social (COUTINHO, 1988, p.106).

Assim, ao observarmos o período de Vargas, podemos visualizar um processo de constante inovaçãoconservação no âmbito político e econômico. Por um lado, os resquícios das velhas oligarquias agrárias conservam-se e se modernizam pela conciliação com a nascente burguesia industrial; por outro lado, as formas produtivas se modernizam com o processo de industrialização, mas mantêm a finalidade de garantir a lucratividade, combinando-se formas arcaicas e modernas de espoliação dos trabalhadores.

Semelhante à realidade italiana no Risorgimento, na passagem dos anos 1920 para 1930, a mudança do padrão de dominação vigente não foi propiciada pela participação de elementos ativos das camadas populares no Brasil. Sendo assim, pensamos que é exatamente na dificuldade de organização das classes subalternas que consiste o óbice a democracia, arraigado na formação do Estado burguês, constituindo o caráter antidemocrático da revolução passiva.

Os entraves da democracia, identificados com as dificuldades para a organização política autônoma das massas populares e, em decorrência, para sua ativação intelectual e moral, apresentavam um caráter sistêmico, isto é, profundamente entranhado na formação do Estado moderno na Itália (ALIAGA, 2016, p. 42) 
Por isso, ao refletir sobre a democracia Gramsci direcionou suas análises para a organização das classes subalternas. Mais especificamente, voltou-se para a questão da democracia no que concerne a formação de intelectuais orgânicos das classes subalternas, para o enfrentamento ao Estado autoritário Italiano (ALIAGA, 2016).

A vista disso, os estudos que se debruçam sobre a revolução burguesa no Brasil aponta que os movimentos que eclodiram de baixo não possuíam uma unidade orgânica e estabilidade no tempo. As reivindicações dos setores subalternos se expressaram no cenário nacional de maneira fragmentária, de modo que não houve uma identidade nas bandeiras de luta. Compreendemos que nesse momento seria necessária uma insurreição das massas populares para que o processo revolucionário de 1930 se caracterizasse, de fato, como uma revolução ativa. No entanto, o que ocorreu foi uma crescente desorganização das massas por parte da repressão aos movimentos e a assimilação dos líderes para compor a base do governo. (SOUZA, 2019).

Nesse sentido, Fernandes (1976) aponta que a dominação burguesa estava associada aos procedimentos autocráticos, enquanto resquícios do passado e inovação do presente, sobretudo porque naquele momento do país não havia constituição e expansão de procedimentos democráticos. Esse momento de transição também marca a passagem do capitalismo da fase concorrencial para a fase monopolista, que culmina na evolução para o Brasil moderno (FERNANDES, 1976). Tal processo também imprime uma particularidade à burguesia que se constitui no Brasil, nos termos do autor:

[...] No caso brasileiro, a burguesia se moldou sob o tipo de capitalismo competitivo, que nasceu da confluência da economia de exportação (de origens coloniais e neocoloniais) com a expansão do mercado interno e da produção industrial para esse mercado [...]. No entanto, a burguesia atinge sua maturidade e, ao mesmo tempo, sua plenitude de poder, sob a irrupção do capitalismo monopolista, mantidas e agravadas as demais condições, que tornaram a sociedade brasileira potencialmente explosiva, com o recrudescimento inevitável da dominação externa, da desigualdade social e do subdesenvolvimento. Em consequência, o caráter autocrático e opressivo da dominação burguesa apurou-se e intensificou-se (FERNANDES, 1976, p. 220).

Conforme aponta Fernandes (1976), a recomposição das estruturas do poder hegemônico marca o início do processo de modernização no Brasil e separa a era senhorial da era burguesa. É importante, portanto, sopesar o aspecto que assumiu a revolução passiva na formação do Estado burguês brasileiro a partir da não realização de uma reforma agrária no país. ${ }^{6}$ Isso reflete de forma particularizada, de certo modo travando a questão do desenvolvimento. No caso do Brasil, em particular, não houve uma alteração das bases de produção.

Nesse sentido, em Estado e capitalismo na "revolução passiva" brasileira, Burity (1988) parte da constatação de que não tivemos no Brasil o surgimento de uma burguesia nos moldes europeus ou americano clássico. Ao contrário desses países, o Brasil possui a singularidade que a burguesia não efetiva a sua dominação com um projeto autônomo como na Europa. Desse modo, nos países latino-americanos o Estado burguês surgiu pela necessidade de regulação do modo de produção capitalista. Aponta ainda Burity, que o Estado consiste um ator fundamental desse processo de constituição do modo de produção. Assim, o Estado que surgiu no Brasil em 1930, assumiu o encargo de generalizar a ordem capitalista para os espaços político, econômico e social da nação, de forma corporativista.

[...] Enfim, a nota mais destoante é atinente ao papel central assumido pelo Estado na modelagem da ordem capitalista excludente brasileira, disciplinando e tutelando a sociedade, de forma a enquadrá-la e torná-la funcional a um esquema de acumulação privada de capital (BURITY, 1988, p. 175).

É certo que a compreensão que se alcança é que esse movimento tornou evidente uma burguesia nacional que era inexistente anteriormente. Segundo Iamamoto e Carvalho (2013), o Estado passa a intervir com a finalidade de garantir a reprodução da hegemonia burguesa, por um lado, integrando diversas categorias sociais de classe média ao bloco dominante, e por outro, reprimindo os trabalhadores e a desorganização dos movimentos políticos, ao tempo em que organiza o consenso através da criação do aparato de legislação trabalhista. Ademais, o Estado assume o papel de legitimar a hegemonia burguesa, conforme apontam Iamamoto e Carvalho (2013),

[...] estabelecendo-se o chamado 'Estado de compromisso', que numa situação de depressão econômica deverá tomar iniciativas tendentes a garantir a reprodução do capital e as taxas de acumulação das diversas frações burguesas, integrar os setores de classe média urbana, ampliando as bases de sua participação política e econômica, e estabelecer mecanismos de controle e desorganização do movimento popular em crescimento (IAMAMOTO; CARVALHO, 2013, p. 160, grifo nosso). 
Para além desses mecanismos, que incrementaram o processo de transformação capitalista no Brasil, Coutinho (1988) chama atenção para um elemento fundamental referente à ação do Estado nesse momento, qual seja: a utilização permanente dos aparelhos repressivos e de intervenção econômica. Nesse sentido, a hegemonia restrita, burguesa, que se alcança no Brasil a partir de 1930, é assentada no aparelho coercitivo do Estado, em outros termos, na potência militar do Estado.

Portanto, reafirmamos que no Brasil, assim como no caso Italiano, não se verificou no momento de formação de uma burguesia autônoma no poder do Estado, bem como o protagonismo decorrente da unificação das camadas populares. Em outros termos, “[...] uma revolução passiva reordena o conjunto das classes dominantes incorporando novos elementos, atraindo parte de suas direções e desarticulando a força antagônica" (DEL ROIO, 2009, p.100). Desse modo, percebe-se que as características antidemocráticas da revolução passiva aparecem através da reação dos dominantes ao subversivismo esporádico e elementar dos grupos subalternos.

\section{Ausência democrática nos marcos da emancipação política no Brasil}

$\mathrm{Na}$ literatura sociológica brasileira, a análise de certo descompasso e/ou desenvolvimento desigual do Brasil combinado à dinâmica do capitalismo mundial, foi realizada por diversos autores ${ }^{7}$, que identificaram o fenômeno, como resultado de um processo incipiente do próprio desenvolvimento do capitalismo periférico, que desde o predomínio colonial à dominação imperialista é perpassada pelos predicados de dependência na economia, na sociedade, na política e na cultura, os quais conferem a seus processos de desenvolvimento, uma forte marca de heteronomia e "modernização conservadora", herdeiras da formação sócio histórica do subcontinente.

No livro A Revolução Burguesa no Brasil, de Florestan Fernandes, encontramos uma análise da revolução dentro da ordem, no sentido de que os sujeitos que atuaram socialmente na direção da 'Independência' e do próprio processo de implantação e desenvolvimento do capitalismo no Brasil, faziam parte da elite político-econômica nativa, subordinados e fortemente comprometidos com a Coroa, o que favoreceu a uma secessão quase pacífica “[...] contribuindo para manter o caráter de 'revolução encapuçada' de todo o processo" (FERNANDES, 1976, p. 32).

Também não é demais notar, que a República liberal se constituiu no Brasil numa sociedade escravocrata, fazendo com que a ausência de um povo, retardasse por decênios a democracia e a "necessidade histórica de forjar uma aliança entre a burguesia nacional e a classe operária, cimentada pelo Estado, para enfrentar o imperialismo e os latifúndios, responsável pela espoliação das riquezas do país" (FAUSTO, 1997, p. 12), favorecendo, com isso o Estado nacional nascente ao patrocínio dos interesses e privilégios particulares dos estamentos.

Também a República, como a Independência, foi fruto de uma mudança 'pelo alto'; foi pouco mais do que um golpe militar; as grandes massas, que continuavam desorganizadas, não participam de sua proclamação. $\mathrm{O}$ arremedo de instituições republicanas criado em seguida não era de molde a fortalecer a sociedade civil. [...] Nossa estrutura social, com a abolição, com os primeiros inícios da 'via prussiana' no campo, começa a se tomar mais próxima da estrutura de uma sociedade capitalista ainda que continue atrasada e fortemente marcada por restos pré-capitalistas; novas classes e camadas sociais se apresentam no cenário político do País (COUTINHO, 2011, p. 22-23).

Talvez, e por isso mesmo, tal particularidade tenha provocado desdobramentos distintos do tipo de organização social proposta pelo liberalismo clássico (que se realiza a princípio, para o cidadão, indivíduo livre e proprietário), instituindo no Brasil, uma forma sui generis de ordenamento político, cuja dependência assume um caráter particular no processo de emancipação do país, com implicações desastrosas para a implantação de um capitalismo nacional, precedido por reformas "democrático-burguesas” (GOMES, 2016).

Este fato parece ter conduzido a um visível afastamento do liberalismo brasileiro em relação aos temas que estiveram no centro da reflexão dos clássicos. Questões como o direito, a lei, o poder, a cidadania e a democracia, não foram assimilados no seu suporte conceitual original, variando em alguns momentos para um sentido contrário àquele, ou convertendo-o à medida da forma desejável de convivência social, o que resultou no ecletismo como princípio filosófico preponderante até a segunda metade do século XIX. Talvez decorra daí, como diz Werneck Vianna (1976, p. 08), "uma profunda mutilação na consciência liberal, que se esvazia do seu conteúdo substantivo, que emprestava consistência a seu discurso, para se transformar no formulário de como produzir e conservar a ordem e a estabilidade sociais".

Encontraremos em Florestan Fernandes (1976, p. 208-209), a chave de leitura explicativa sobre o padrão de dominação burguesa no Brasil, “[...] algo que se iniciara no último quartel do século XIX, quando o envolvimento da aristocracia agrária pelo "mundo urbano dos negócios" se tornou mais intenso e apresentou 
seus principais frutos políticos". Particularmente é entre os anos 1930, considerada pelo autor como a primeira fase da revolução burguesa brasileira, onde as alianças e o rearranjo entre a velha oligarquia e a burguesia industrial nascente, favorece a conciliação de seus interesses, assumindo, a partir do golpe do Estado Novo em 1937 uma ampla expressividade no âmbito político, cujas características peculiares da elite dominante estavam associadas à cúpula militar e aos quadros técnicos do Estado.

O período autoritário que ficou conhecido como Estado Novo teve início no dia 10 de novembro de 1937 com um golpe liderado pelo próprio Presidente Getúlio Vargas e apoiado, entre outros, pelo general Góes Monteiro. Para que ele fosse possível, foi preciso eliminar as resistências existentes nos meios civis e militares e formar um núcleo coeso em torno da ideia da continuidade de Vargas no poder. Esse processo se desenvolveu, principalmente, ao longo dos anos de 1936 e 1937, impulsionado pelo combate ao comunismo e por uma campanha para a neutralização do então governador gaúcho Flores da Cunha, considerado, por seu poder político e militar, um obstáculo ao continuísmo de Vargas e à consolidação de um Exército forte, unificado e impermeável à política $(\mathrm{FGV} ; \mathrm{CPDOC}, 1997, \mathrm{~s} / \mathrm{p})^{8}$.

No decurso dessa história, a programática do governo Vargas foi de responder ao enfretamento das classes dentro de uma estratégia de criação da legislação trabalhista. O Ministério do Trabalho, na perspectiva de legalidade do enfrentamento da "questão social”, aparece como marco da funcionalidade à construção da hegemonia burguesa. Aos poucos, o projeto que se entreteve e se impôs a todos, tentou apagar da legislação as marcas das lutas operárias dos anos 1920. Nesse movimento, transformou o que poderia ser incorporado como direito de cidadania numa doação, dando corpo ao que veio ser denominado de ideologia da outorga (GOMES, 2016).

A ideologia da outorga será sem dúvida, resultante de um pacto. Porém, não entre o Estado e as classes subalternas, e sim entre as diferentes facções das classes dominantes, tendo como principal implicação a [...] supressão da memória das classes subalternas, que apareceriam como impotentes e incapazes de reivindicar seus direitos elementares por si sós (VIANNA, 1999, p. 32).

Se isto é correto, pode-se dizer que é no marco de uma República com feições autocrática, conservadora e autoritária que se forjou no país a autonomia política, constituindo o que Schwarz (2005) nomeou de ideologia do favor. Considerada como a mediação política mais genérica no Brasil, nos auxilia na compreensão do desenvolvimento capitalista, operado continuamente contra o 'atraso' e por meio de estruturas de poder vinculados ao mando, ao coronelismo, ao nepotismo e episodicamente, mediante inspiração fascista.

No caso brasileiro como no dos outros países latino-americanos, a democracia liberal correspondia ao liberalismo oligárquico. Não por acaso a marca dominante do sistema político vigente entre 1930 e 1945 foi à ditadura autoritária, informal (Governo Provisório) ou formal (Estado Novo), cortada apenas pelos anos 1934-1937, em que as liberdades democráticas foram sendo suprimidas (FAUSTO, 1997, p. 23).

Portanto, é vastamente conhecida na literatura da formação social brasileira a complexidade do desenvolvimento capitalista no país e o real papel do Estado e das classes sociais no processo de emancipação política, que nos limites de um artigo não cabe explicitar. Contudo, se pudéssemos fazer uma rápida retrospectiva do correr dos acontecimentos, diríamos que na experiência brasileira há uma ausência de regras no tipo de regulação econômica, que Chico de Oliveira denomina de regulação ad hoc (1998), marcada pelo predomínio das elites burguesas e de uma esfera pública estatal voltada para fortalecer os seus interesses e promover a expansão capitalista a qualquer custo:

A formação da sociedade brasileira, se a reconstituirmos pela interpretação de seus intelectuais 'demiúrgicos', a partir de Gilberto Freire, Caio Prado Jr., Machado de Assis, Celso Furtado e Florestan Fernandes, é um processo complexo de violência, proibição da fala, mais modernamente privatização do público, interpretado por alguns com a categoria de patrimonialismo, revolução pelo alto, e incompatibilidade radical entre dominação burguesa e democracia; em resumo de anulação da política, do dissenso (OLIVEIRA, 1987, p. 59).

Uma leitura atenta do pensamento social brasileiro nos permite identificar o conjunto de determinações que se interpôs na sua formação social e a particularidade com a dinâmica do capitalismo mundial. A literatura mostra que a emergência por uma autonomia política no país, se realizou sem que pudesse existir uma revolução democrática pela independência, o que significa dizer que os laços coloniais com a metrópole portuguesa não foram superados, ao contrário, permaneceu ao longo da trajetória da velha República e se estendeu pela 
nova. De fato, meio século de desenvolvimento capitalista não foi suficiente para romper com o caráter do Estado oligárquico no Brasil, do qual a tendência de se impor pelo alto é ilustrativa e cuja insistência desde 1822 (estrutura republicana) de caráter arbitrário, sempre é canalizado por acórdãos entre os interesses oligárquicos, a burguesia nacional e imperialista. Tendência que se reproduz ao largo da vida nacional republicana, onde a forma política democrática cumpre um papel meramente subsidiário.

A forma política brasileira continua sendo um Estado burguês que tem por principal característica organizar o domínio de uma pequena parte da sociedade (na origem uma aliança burguesa oligárquica que se desenvolveu para um bloco burguês monopolista em aliança com o imperialismo e o latifúndio, culminando num bloco monopolista em seus diferentes segmentos com o capital imperialista) sobre a maioria da população, dos trabalhadores e demais segmentos explorados pela ordem capitalista burguesa, que só podem chegar a uma inserção precária na ordem democrática, nos termos de uma democracia de cooptação ou restrita (IASI, 2019, p. 420).

Essas premissas nos permitem arriscar dizer, que o pacto pelo alto, como característica da revolução passiva brasileira e mecanismo vastamente utilizado pelo Estado desde os anos 1930, progride para formas mais avançadas e orgânicas e assenta-se, não só pela grande fragilidade da democracia burguesa liberal, mas pelas debilidades organizacionais autônomas da classe trabalhadora no país. A velha relação política, contudo, se conserva através da aliança entre frações de classe da burguesia com as arcaicas oligarquias que resistem no país, organizadas ao nível do Estado. E com isso, a dominação da classe burguesa se impõe, seja de forma autoritária ou democrática, constituindo a sua hegemonia baseada na sobreposição da força ao consenso nos âmbitos da sociedade civil e da sociedade política. É por assim dizer, tarefa do Estado desorganizar e absorver continuamente as lideranças das classes subalternas por meio de seus aparelhos burocráticos, impedindo-as de ter maior expressão na política nacional.

É inegável e a história tem mostrado, que nos países onde a democracia burguesa se fortaleceu, redundaram em benefícios aos trabalhadores. Mas também é verdade o fato de que elas só se realizaram muito pontualmente, o que faz permanecerem válidos os argumentos de Marx de que revoluções políticas não significam em hipótese alguma, revolução social ${ }^{9}$. Como se sabe incorreram neste equívoco toda a tradição de esquerda social-democrática, que utilizaram como método tático à democracia burguesa em substituição a estratégia revolucionária em direção ao socialismo, passando desde Kautsky até o revisionismo de Bernstein ${ }^{10}$. Um balanço atento desse quadro mostrará que a perspectiva da democracia socialista, pressupõe a direção de um projeto orientado na construção de uma alternativa contra a ordem e exigirá uma crítica amarga e contundente à cultura política contemporânea da ordem (GOMES, 2007).

\section{Considerações Finais}

Com o esforço de síntese procuramos fazer uma breve reflexão sobre a particularidade dos problemas estruturais do Estado capitalista brasileiro, os quais exige um aprofundamento maior sobre os estudos historiográficos da revolução burguesa no Brasil e da formação social brasileira.

Para a tradição marxista que reflete a questão dos países periféricos marcados pelo imperialismo, colonialismo, neocolonialismo e outras formas de relações hierárquicas de domínio nestas nações; a formação de um projeto de poder que acaudilha as classes e sua correlação de forças com a política do Estado nos países do subcontinente, desde sempre esteve às voltas com uma questão crucial: a relação subordinada que elas estabelecem com os países capitalistas centrais e impede a todo custo à realização das tarefas democrático-burguesas.

No artigo procuramos demonstrar que o processo da revolução burguesa brasileira possui traços que constituem na particularidade da sua identidade, semelhante experiência nacional da realidade italiana no período do Risorgimento. Desse modo, em razão dessas determinações foi possível entender esse processo através da tradução da revolução passiva.

Como se depreende do que foi tratado aqui, concluímos que a forma de reprodução de relações sociais que incidem nos marcos da emancipação política brasileira da nova República, avança para formas orgânicas antidemocráticas na ditadura com Vargas (1930-1937). O fenômeno de determinação pelo alto como descrevemos, é antes de tudo, um processo ordinário da forma política imposta pelo capitalismo dependente, e, portanto, necessário no controle político dos trabalhadores pelos Estados modernos que não insurgiram de revoluções jacobinas, a exemplo da experiência Italiana e brasileira. Se constitui como mecanismo da revolução passiva e como uma forma também de evitar sublevações. 
Em nossa reflexão crítica, consideramos que a chave de leitura marxista do Brasil se apresenta como uma resposta ao tema da principal particularidade da formação social: a cultura restritiva e antidemocrática que conforma o projeto político da burguesia brasileira, cristalizada através do Estado, que tem se mostrado em todos os sentidos avesso a ideia de reformas sociais, o que contribuiu para que se criassem no país, instituições eminentemente carnavalescas que só servem para legitimar os cartolas em seu brutal domínio de classe. É fato que a burguesia brasileira não carrega consigo um projeto soberano de desenvolvimento, isto é, um projeto de Nação. E mesmo no período de instituição do Estado democrático de direito (a partir de 1985) o estilo patrimonialista é mantido e traduzido na condição de "Estado Cartorial" (HÉLIO JAGUARIBE, 1950) a qual expressa um capitalismo burocrático com políticas clientelistas, para garantir benesses, vantagens e lobbies específicos para certos indivíduos e grupos sociais e adornados por uma classe dominante limitada, que sempre manteve sob seu domínio e controle o poder, enquanto a maioria da população vive e é levada a mais brutal marginalização socioeconômica, política e cultural.

Nesse sentido, não parece estranho que a forma política, que se construiu no Brasil, por meio da ideologia da autorga, há décadas se revela por meio de avanço e retrocesso; rupturas e continuidades. Contradições do capitalismo brasileiro sui generis que de alguma maneira e no imaginário social hipotecaram a possibilidade e "o desejo de construção de um país mais igualitário" (CEVASCO, 2016, p. 277), que parecia caminhar em uma direção social "civilizada" e com um projeto democrático inclusivo. O desfecho autoritário na conjuntura atual, só revela o caráter preventivo do Estado brasileiro, que ante qualquer ameaça de subversivismo popular e sob o discurso semelhante da década de 1930 "de purificar o regime e republicanizar a república" (SODRÉ, 1985), aciona as forças mais reacionárias das frações de classe no poder e faz erodir as forças predatórias do capitalismo dependente.

\section{Referências}

ALIAGA, L. Gramsci e a critica a teoría das elites. Revista Crítica Marxista, n. 42. São Paulo, p. 26-42, 2016. ARICÓ, J. La cola del diablo: Itinerário de Gramsci na América Latina. Buenos Aires: Punto Sur, 1988.

BURITY, J. Estado e Capitalismo na Revolução Passiva Brasileira. Cadernos de Estudos Sociais, v. 4, n. 2, jul./dez. 1988.

CEVASCO M. E. In: SINGER, André; LOUREIRO, Isabel (org.). As contradições do lulismo - A que ponto chegamos. São Paulo: Boitempo, 2016.

COUTINHO, Carlos Nelson. Cultura e sociedade no Brasil: ensaios sobre ideais e formas. 4 ed. São Paulo: Expressão Popular, 2011. As categorias de Gramsci e a realidade brasileira. In COUTINHO, C.N e NOGUEIRA, M.A(Org). Gramsci e a América Latina. Rio de Janeiro: Paz e Terra, 1988, p. 103-127.

DEL ROIO, M. T. A mundialização capitalista e o conceito gramsciano de revolução passiva. In MENDONÇA; SILVA; MILLER (Orgs.). Marx, Gramsci e Vigotski: aproximações. São Paulo: Cultura Acadêmica, 2009.

DEMIER, F. A lei do Desenvolvimento desigual e combinado de León Trotsky e a intelectualidade brasileira. Outubro Revista, ed. 16, 2007. Disponível em: http://outubrorevista.com.br/a-lei-do-desenvolvimento-desigual-e-combinado-de-leon-trotsky-e-a-intelectualidadebrasileira/. Acesso em: 20 jun. 2019.

FAUSTO, Boris. A Revolução de 1930: historiografia e história. 12. ed. São Paulo, Brasiliense, 1989.

FERNANDES, F. A revolução burguesa no Brasil: ensaio de interpretação sociológica. 2. ed. Rio de Janeiro: Zahar, 1976.

FUNDAÇÃO GETÚLIO VARGAS (FGV). CENTRO DE PESQUISA E DOCUMENTAÇÃO DE HISTÓRIA CONTEMPORÂNEA DO BRASIL (CPDOC). A Era Vargas: dos anos 20 a 1945. Disponível em: https://cpdoc.fgv.br/producao/dossies/AEraVargas1/ anos30-37/GolpeEstadoNovo. Acesso em: 10 jul. 2019.

GRAMSCI, A. Cadernos do cárcere: O Risorgimento. Notas sobre a história da Itália. Tradução de Luiz Sergio Henriques com a colaboração de Carlos Nelson Coutinho e Marco Aurélio Nogueira. Rio de Janeiro: Editora Civilização Brasileira, 2002. v.5.

GOMES, Cláudia. M. C. O choque neoliberal e o padrão de hegemonia burguesa do lulo-petismo. R. Katálysis, Florianópolis, v. 21, n. 1, p. 86-95, jan./abr. 2018.

Em Busca do Consenso: Radicalidade democrática e afirmação de Direitos. 2. ed. Rio de Janeiro: Lumen Juris, 2016.

A Centralidade do Direito na cultura politica contemporânea... 2007. 279 fl. Tese (Doutorado em Serviço Social), Programa de

Pós-Graduação em Serviço Social, Universidade Federal de Pernambuco, Recife.

IAMAMOTO, M. V.; CARVALHO, R. de. Relações sociais e Serviço Social no Brasil: esboço de uma interpretação históricometodológica. 39. ed. São Paulo: Cortez, 2013.

IANNI, Octavio. A dialética da história. In: História e ideal: ensaios sobre Caio Prado Junior. (Org.). Maria Ângela D’́incao. São Paulo: Unesp/Brasiliense, 1989.

IASI, M. Cinco Teses sobre a formação social brasileira. Serv. Soc. Soc., São Paulo, n. 136, p. 417-438, set./dez. 2019. Disponível em: http://www.scielo.br/scielo.php?pid=S0101-66282019000300417\&script=sci_arttext\&tlng=pt.

JAGUARIBE, H. Política ideológica e política de clientela. Jornal do Comércio, São Paulo de 14/5/1950 e em Digesto Econômico, v. 6, n. 68 , p. 41-62, [19-]. 
LIGUORI, G; VOZA, P. (orgs.) Dicionário Gramsciano. São Paulo: Boitempo, 2017.

LÊNIN, V. I. O desenvolvimento do capitalismo na Rússia. São Paulo: Abril Cultural, 1982.

MARX, Karl. A burguesia e a contrarrevolução. (Trad.) J. Chasin, et ali. São Paulo, Ensaio, 1987.

NOBRE, M. Imobilismo em movimento: da abertura democrática ao governo Dilma. São Paulo: Companhia das Letras, 2013.

OLIVEIRA, F. Vanguarda do atraso e atraso da vanguarda: Globalização e Neoliberalismo na América Latina. Praga: Revista de Estudos marxistas, São Paulo, n. 4, p. 31-42, dez. 1997.

OLIVEIRA, F. A economia brasileira: crítica à razão dualista. Petrópolis, Rio de Janeiro: Vozes, 1987.

SCHWARZ, Roberto. Cultura e política. 2. ed. São Paulo: Paz e Terra, 2005.

STEPAN, A. Democratizando o Brasil. Paz e Terra, 1988, p.12-13.

SODRÉ, Nelson Werneck, O Tenentismo, Mercado Aberto, Porto Alegre, 1985.

SOUZA, Ana. Karoline Nogueira A atuação dos militares na revolução passiva brasileira. 2019. 155 f. Dissertação (Mestrado em Serviço Social)"Programa de Pós-Graduação em Serviço Social, Universidade Federal da Paraíba, João Pessoa, 2019.

. GOMES, Cláudia. M. C. A Categoria Revolução Passiva nos Cadernos do Cárcere e nos intérpretes brasileiros. In: ENCONTRO

NACIONAL DE HISTÓRIA POLÍTICA HISTÓRIA, RUPTURAS INSTITUCIONAIS E REVOLUÇÕES, João Pessoa, 2017. Anais [...]. João Pessoa, 2017.

GOMES, Cláudia. M. C. A Revolução Passiva na particularidade brasileira do Lulo-petismo. In: XXXI Congreso Asociación Latinoamericana de Sociología, 2017, Montevideo -Uruguay. Anais do Alas 2017. ISBN 978-9974-8434-7-9.

Trotski, L. “¿Qué deben hacer los bolcheviques-leninistas en España? (Carta a un amigo español). In: Escritos sobre la revolución española [1930-1940]. Fundación Federico Engels, Madrid, 2010.

ZIZEK, Slavoj. Trotsky - Terrorismo y Comunismo: Slavoj Zizek presenta a Trotsky. (Trad.) Alfredo Brotons Muñoz. Ediciones Akal, e-Book Kindle, 2009.

TOLEDO, C. As esquerdas e a redescoberta da democracia. São Paulo: Brasiliense, 1994.

VIANNA, Luís Werneck. A Judicialização da política e das relações sociais no Brasil. Rio de Janeiro, Revan, 1999.

. Liberalismo e sindicato no Brasil. Rio de Janeiro, Paz e terra, 1976.

\section{Notas}

1 Cf.: STEPAN,A.Democratizando o Brasil (1988 p. 12-13). “(...)É justamente essa liberalização controlada, iniciada em 1973, que resultará, mais de uma década depois, no processo de democratização, também controlado, sobretudo inicialmente, pelos detentores do poder autoritário”.

2 O artigo é resultado do esforço analítico e acumulativo das pesquisas desenvolvidas no âmbito da Pós-graduação (Mestrado e Pós-doutorado), os quais integram o Grupo de Estudos e Pesquisas em Economia Política Trabalho (GEPET/UFPB) cadastrado no Diretório Geral de Pesquisadores/ CNPq.

3 Cf.: TOLEDO, C. As esquerdas e a redescoberta da democracia (1994, p. 114). “(...) Até meados dos anos 1960, a esquerda brasileira hegemonizada pelo PCB, estava mobilizada em torno das reformas sociais, das campanhas nacionalistas e da defesa do desenvolvimento econômico. Aquestão democrática, até recentemente, aparecia ora subordinada, ora com uma importância secundária na reflexão teórica e na luta ideológica. Não se deixava de afirmar a necessidade da defesa da legalidade democrática diante da permanente ameaça golpista da direita, mas nos anos 1950-60 - a questão nacional - como afirmavam os isebianos, a luta pela constituição da Nação - tinha inteira primazia. [...] Enquanto o desenvolvimento econômico e as reformas estruturais não se efetivassem, a democracia política não deixaria de ser "formal" ou "abstrata" para o conjunto dos trabalhadores e das massas populares".

4 Cf.: DEMIER, F. A lei do Desenvolvimento desigual e combinado de León Trotsky e a intelectualidade brasileira (2007, p. 89). “(...) Partilhavam dessa concepção especialmente os formuladores teóricos do Partido Comunista (PCB) e os intelectuais vinculados à Comissão Econômica para aAmérica Latina (CEPAL). Para esta vasta gama de pensadores, o Estado ‘subdesenvolvido' (ou feudal/semi-feudal, segundo os pecebistas), dos países latino-americanos se explicaria essencialmente em função de uma relação externa dicotômica (Imperialismo X Nação), na qual a subordinação desses ao imperialismo significava um "entrave" aos seus desenvolvimentos capitalistas".

5 Cf.: SOUZA, Ana Karoline Nogueira. A Atuação dos militares na revolução passiva brasileira (2019, p. 108). “(...) A partir da aproximação da concepção gramsciana de tradutibilidade é possível o exercício da tradução a partir de duas realidades semelhantes e reciprocamente traduzíveis. A tradução não trata de um esquema lógico de aplicação das categorias de análise a diferentes contextos, uma vez que cada realidade nacional possui elementos particulares que configuram a sua identidade, o que inviabiliza a tradução integral de todos os elementos que a compõem".

6 Não pretendemos aprofundar a análise da temática em questão neste artigo. Para uma análise mais detalhada Cf. PRADO JR., C. A Questão Agrária. 1. ed. São Paulo: Brasiliense, 1987.

7 A título de nota, é importante destacar a contribuição das principais referências do pensamento social brasileiro, a exemplo de Caio Prado Junior, que “[...] inaugurou uma interpretação marxista da formação social brasileira, estabelecendo um horizonte intelectual novo, sem o qual não foi mais possível pensar a história e o pensamento no Brasil“", conforme informa Octávio Ianni (1989, p. 64). É de Prado Junior a indicação do conceito de 'via prussiana' e 'modernização conservadora' na análise segundo a qual é possível observar o desenvolvimento do Brasil como desigual e combinado. Para Ricupero (2000, p. 235), “[...] Caio Prado notou que o que marca países como o nosso, que estão entre a civilização e a barbárie e que não são, portanto, nem Oriente nem Ocidente, é esse convívio promíscuo entre o moderno e o arcaico, que se explica pela forma como o 
moderno se utiliza aqui do arcaico“.Éimportante destacar, a posição de José Luiz Fiori em Sonhos Prussianos, Crises Brasileiras - Leitura política de uma industrialização Tardia. In: Em Busca do Dissenso Perdido, 1995, donde polemiza sobre as análises que apontam o processo tardio de desenvolvimento do Brasil pela ótica da "via prussiana". Igualmenteé referência nessa análise a contribuição dos estudos de Florestan Fernandes, em particular seu texto A Revolução Burguesa no Brasil, 1975, obra em que vai fazer uma análise exaustiva de interpretação do Brasil, a partir da interlocução com Prado Junior sobre a questão nacional. A referência ao conceito de "revolução burguesa"é para ele uma chave de explicação para o processo de desenvolvimento do país, donde o padrão burguês de civilização transformou-se em necessidade sócio histórica.

8 Cf. FGV/CPDOC-Centro de Pesquisa e Documentação de História Contemporânea do Brasil. A Era Vargas: dos anos 20 a 1945. Disponível em: https://cpdoc.fgv.br/producao/dossies/AEraVargas1/anos30-37/GolpeEstadoNovo. Acesso em 18 de set. 2019

9 Cf.: MARX, Karl. A burguesia e a contrarrevolução. (Trad.) J. Chasin, et ali. São Paulo, Ensaio, 1987.

10 Cf.: ZIZEK, Slavoj. Trotsky-Terrorismo y Comunismo: Slavoj Zizek presenta a Trotsky. (Trad.) Alfredo Brotons Muñoz. Ediciones Akal, eBook Kindle, 2009.

\section{Cláudia Maria Costa Gomes}

claudiac_gomes@hotmail.com

Pós-doutorado em Economía Internacional y Desarrollo pela Universidad Complutense de Madrid (UCM)

Professora da Universidade Federal da Paraíba (UFPB)

\section{Ana Karoline Nogueira de Souza}

karolns10@hotmail.com

Mestre em Serviço Social pela Universidade Federal da Paraíba (UFPB)

\section{UFPB/CCHLA}

Universidade Federal da Paraíba, Campus I, Jardim Cidade Universitária

João Pessoa - PB

CEP: 58033-455

\section{Agradecimentos \\ Não se aplica. \\ Agência financiadora \\ Não se aplica.}

\section{Contribuições das autoras}

A construção do artigo teve igual contribuição das autoras.
Aprovação por Comitê de Ética e consentimento para participação

Não se aplica.

Consentimento para publicação

Consentimento das autoras.

Conflito de interesses

Não há conflito de interesses. 